\title{
Effective Recovery of Methane from Coal Mine Methane Gas by Vacuum Pressure Swing Adsorption: A Pilot Scale Case Study
}

\author{
Andrzej Olajossy* \\ Department of Mining and Geoengineering, AGH University of Science and Technology, Kraków, Poland \\ *Corresponding author: olajossy@agh.edu.pl
}

Received April 28, 2013; Revised June 28, 2013; Accepted June 30, 2013

\begin{abstract}
The course and results of experimental studies of efficient methane separation from mining gases mixture, performed at a pilot plant, are presented in the paper. It was indicated and justified that appropriate modifications should be realized in the vacuum pressure swing adsorption (VPSA) method along with (PSA) method for improving of efficient technology of methane recovery from coal mine methane gas. Those studies were preceded by experiments at laboratory scale. The results of experiments at pilot scale created bases for preliminary assumptions for the planned project of industrial scale installation. The pilot plant was made in the Coal Mine "Pniówek" J.S.W. S.A., Silesian Basin, Poland, where in the raw gas from drainage methane gas from coal beds are: on average about $53 \mathrm{vol} \% \mathrm{CH}_{4}$, as well as nitrogen, oxygen and carbon dioxide. On the basis of experimentally established optimum work conditions of the pilot plant the gas was enriched forming the methane-rich gas 96 vol\% $\mathrm{CH}_{4}$. Then the efficiency of methane separation reached $90-92 \%$ while the re-circulated methane to feed gas ratio changed within q=1.0 - 1.2. High-methane gas of such good quality, obtained at so high recovery efficiency, can be introduced to the high-methane gas network.
\end{abstract}

Keywords: vacuum pressure swing adsorption, coal mine gas, methane separation, pilot plant

Cite This Article: Olajossy, Andrzej, "Effective Recovery of Methane from Coal Mine Methane Gas by Vacuum Pressure Swing Adsorption: A Pilot Scale Case Study.” Chemical Engineering and Science 1, no. 4 (2013): 46-54. doi: 10.12691/ces-1-4-1.

\section{Introduction}

One of the earlier works on separation of methane from nitrogen through adsorption was written by Baksh et al. [1]. A detailed description of pressure swing adsorption methods can be found in Ruthven et al. [2]. Later works touching the same problems were mostly devoted to modelling of the PSA process when employed to separate methane-nitrogen mixtures, e.g. patents specifications $[3,4]$. In some of these works the mixtures of gases had to be available at a high pressure, which enabled multigrade lowering of pressure during successive separation processes. However, patents specifications on methane separation from mine gases have been hardly available so far.

High quantities of methane occur in beds of numerous coal basins in the World. In Poland the coal mine methane (CMB) is mainly present in the Silesian Basin and its balance reserves are 85.9 milliard cubic metres. Methane gases released from coal beds during their exploitation are partly disposed of through the ventilation shafts to the surface, and the remaining part is directed to the methane drainage station. Methane gases from this station contain: $40-60 \% \mathrm{CH}_{4}, 7-8 \% \mathrm{O}_{2}, 2-4 \% \mathrm{CO}_{2}, \mathrm{H}_{2} \mathrm{O}$ in saturation state, and the rest is $\mathrm{N}_{2}$. Such methane gas, on average $50 \% \mathrm{CH}_{4}$, can be directly used for energy purposes on the mine's area, though generally it constitutes a precious source of energy for utilization purposes. Its concentration can be easily increased to that of saleable gas (ca. $75 \% \mathrm{CH}_{4}$ ) or more ambitiously, to those of network gas (over 95 vol\% $\mathrm{CH}_{4}$ ).

For this purpose, the mine gas has to be dried, $\mathrm{CO}_{2}$ and other contaminations removed. As a consequence a bicomponent mixture of methane and nitrogen with oxygen is obtained. Being interts they are treated as one component in a proper technology. This is a modified technology PSA, version VPSA (Vacuum Pressure Swing Adsorption), which enables effective separation of methane from nitrogen with oxygen, after activated carbon has been specified as sorbent.

Though rarely used for methane mine gases separation, the VPSA method is fit for processing raw gases in the range of $1000-10000 \mathrm{~m}^{3}$ (STP) per hour. Membrane methods and cryogenic gas separation methods should be applied for smaller and greater quantities of gas, respectively. This is also related with the comparison of capital cost and the operation cost of those methods.

At the AGH University of Science and Technology, Poland scientists undertook researches on efficient enriching of mine gases in methane. Firstly, an appropriate concept of VPSA method was elaborated, which was a result of co-operation of AGH-UST and Institute of Heavy 
Organic Synthesis in Kędzierzyn, Poland. The appropriate sorbents were selected, computer simulations of the VPSA process were made, parameters of the model identified, and the course of the VPSA process was experimentally investigated in cyclically repeatable stages [2]. The following part of investigations was of application-implementation character and was realized in co-operation of AGH-UST and the Silesian Coal Concern J.S.W., Poland. The design assumptions were worked out and an experimental pilot plant producing high-methane gas in the Coal Mine "Pniówek", Poland worked out. That valuable gas could be produced at industrial scale and delivered to local networks or to gas transport networks. The meritoric description of those investigations and their results are presented below.

It must be noted, that this article presents original results obtained in numerous researches conducted in real conditions in a coal mine. Those actions are shown which lead to the achieved goal. Even though this paper is broad, there was unfortunately no place for certain detailed remarks. However, reference is made to Author's previous article and his patent. In this article references no works are mentioned, which utilize a zeolite molecular sieve, because sorbents of that type are not used for mine gas separation.

\section{Some Criteria and Conditions of Effective Separation of Gases in A Pilot Plant}

The typical composition of coal mine methane is not favourable for gas separation methods since it is not easy to separate methane from nitrogen with oxygen $\left(\mathrm{N}_{2}+\mathrm{O}_{2}\right)$ and to keep the operating cost reasonably low at the same time. Coal bed methane gases are specific. To efficiently separate methane from the remaining components of the mine gases mixture it is rather the vacuum pressure swing adsorption VPSA method which after prior modifications should be used, not the classic PSA method. The modification of the separation process becomes important since the considered gases are hard-to-separate; both nitrogen and oxygen have to be separated from methane precisely and both of them at the same time. To meet this goal, the processes should be controlled by the diffusion mechanism for gas molecules in the transport pores of properly selected sorbent and by the adsorption equilibrium conditions. Those two conditions were accounted for both in previous laboratory studies [5], and at presented pilot-experimental scale, which should be successively implemented at industrial scale. The mixture of raw mine gases should be always dried and cleaned of various contaminations; at least carbon dioxide should be partly removed from it. Therefore, after selecting proper sorbent, guaranteeing that nitrogen and oxygen will adsorb on it identically, only a two-component: methane-nitrogen with oxygen system can be separated. In previous experiments performed at laboratory scale, the separation of such a system (devoid of carbon dioxide) was carried out with the use of four basic technological operations, i.e. adsorption stage, counter-current rinse stage, desorption stage, pressurization - with feed with re-pressurization stage. The whole quantity of gas from desorption was recirculated and directed to rinsing operation.

It was partly concluded from the previously obtained numerical simulation of the VPSA process that the separation of bi-component system should be controlled by the adsorption equilibrium conditions. The following criteria were considered when selecting a suitable activated carbon grade:

- high selection for methane versus nitrogen with oxygen;

- high adsorption capacity versus nitrogen with oxygen;

- low difference between possible values of diffusion coefficient for methane and nitrogen with oxygen in transport pores of activated carbon

- price of activated carbon.

Such properties could be found in activated coal G2X7/12 from Shirasagi End. Div. Japan, selected from among other analyzed sorbents. The characteristics of that sorbent are presented in Table 1. Some data in this Table, e.g. pore surface expressed in square meters per gram are taken directly from the producer of the sorbent, i.e. Shirasagi Eng. Div. Japan. Adsorption isotherms for methane and nitrogen were found with the use of a standard volumetric method at temperatures $273 \mathrm{~K}$ and $298 \mathrm{~K}$. The values $\mathrm{a}^{\infty}{ }_{\mathrm{i}}, \mathrm{b}_{\text {io }}$ and $\left(-\Delta \mathrm{H}_{\mathrm{i}}\right)$ were calculated on the basis of Langmuire adsorption isotherms and van't Hoff-Clapeyron equation. In this calculations a procedure was used that is presented in a work [5]. It is worth noting that the adsorption kinetics was investigated experimentally and their parameters were established with Gluckauf equation for adsorption kinetics.

Table 1. Specification of activated carbon G2X7/12

\begin{tabular}{|c|c|}
\hline Pore surface as found by BET/ $\mathrm{N}_{2}$ method & $1007.2 \mathrm{~m}^{2} \mathrm{~g}^{-1}$ \\
\hline Pore surface per Langmuir isotherm & $1343.3 \mathrm{~m}^{2} \mathrm{~g}^{-1}$ \\
\hline Pore volume & $0.4964 \mathrm{~m}^{2} \mathrm{~g}^{-1}$ \\
\hline Average pore diameter & $1.471 \mathrm{~nm}$ \\
\hline Diameter of dominant pores & $3.00 \mathrm{~nm}$ \\
\hline Diameter of transport pores & $1090 \mathrm{~nm}$ \\
\hline Saturation constant $a^{\infty}(273 \mathrm{~K})$ & $3.32 \mathrm{~mol} \mathrm{~kg}^{-1}$ \\
\hline Saturation constant $a^{\infty}(298 \mathrm{~K})$ & $3.30 \mathrm{~mol} \mathrm{~kg}^{-1}$ \\
\hline \multicolumn{2}{|c|}{ Affinity constant $\left(\mathrm{dm}^{3} \mathrm{~mol}^{-1}\right)$ : } \\
\hline $\mathrm{b}_{\mathrm{CH}_{4}}(273 \mathrm{~K})$ & 25.36 \\
\hline $\mathrm{b}_{\mathrm{CH}_{4}}(298 \mathrm{~K})$ & 4.1112 .99 \\
\hline $\mathrm{b}_{\mathrm{N}_{2}}(273 \mathrm{~K})$ & 2.97 \\
\hline \multicolumn{2}{|c|}{ Methane/nitrogen equilibrium selectivity } \\
\hline $\mathrm{K}_{\mathrm{CH}_{4} / \mathrm{N}_{2}}(273 \mathrm{~K})$ & 6.17 \\
\hline $\mathrm{K}_{\mathrm{CH}_{4} / \mathrm{N}_{2}}(298 \mathrm{~K})$ & 4.38 \\
\hline \multicolumn{2}{|c|}{ Isosteric heat of adsorption, $\mathrm{J} \mathrm{mol}^{-1}$} \\
\hline$-\Delta \mathrm{H}_{\mathrm{CH}_{4}}$ & 18.100 \\
\hline$-\Delta \mathrm{H}_{\mathrm{N}_{2}}$ & 8800 \\
\hline
\end{tabular}

The analysis of Table 1 reveals that the value of selectivity coefficient of methane and nitrogen at temperature $273 \mathrm{~K}$, i.e. $\mathrm{K}_{\mathrm{CH} 4 / \mathrm{N} 2}=6.17$ was better than at temperature $298 \mathrm{~K}$, i.e. $\mathrm{K}_{\mathrm{CH} 4 / \mathrm{N} 2}=4.38$. However, the realization of the VPSA technology at such a low temperature may increase the cost, which requires additional consideration. It should be emphasized that the pore surface of thin micropores in that sorbent was well developed. 
The analysis of laboratory studies and computer simulations presented in [5] showed that the efficiency of the VPSA method also depended on other conditions. It was necessary that the gas with increased content of methane were re-circulated in such quantities, that the ratio of methane and carbon dioxide molar rate in this gas to the methane and carbon dioxide molar rate in feed gas was possibly low, not much above unity. Attempts should be also made to use the methane-lean gas (about $12 \% \mathrm{CH}_{4}$ ) from adsorption operation in the process. Economically favourable lowering of that ratio value and unfavourable loss of methane from methane-lean gas negatively influenced the efficiency of methane recovery as under such process conditions the efficiency changed within $\eta=86-89 \%$. To obtain high-methane product with methane content of $96-98$ vol\% $\mathrm{CH}_{4}$, the methane content in the lean gas from adsorption stage was $11-15$ vol\% $\mathrm{CH}_{4}$ and the inerts content in waste gas equalled to $85-89$ vol\%. Methane content in the adsorption stage effluent gas could be regulated as it depended on desorption stage vacuum pressure and on sorption capacity for methane.

Fulfilling those conditions should be adequate to the ways in which gas separation process operations were realized. Moreover, when the methane sorption wave was brought to the outlet point of the sorption bed at adsorption stage, and then when the methane sorption wave was brought to the entry point of the sorption bed at the counter-current rinse stage, the gas separation process became sensitive to changes in the gas flow rate in individual operations.

Even a slight increase in the flow rate of the methanelean gas, and hence a slight increase in the flow rate of the feed gas, resulted in moving the methane sorption wave beyond the bed. Thus, the methane content would be increased in the plant effluent gas at the adsorption stage. Similarly, a slight increase in the flow rate of the methanerich gas, which was re-circulated to the rinse operation would result in moving the methane sorption wave beyond the bed. Consequently, higher doses of methane will be introduced to the process at the adsorption stage and this, in turn, would move the methane sorption wave away from the bed. As a result, the methane content would become excessive in the methane-lean gas, which leaves the plant at the adsorption stage.

Some of the presented criteria and conditions became basis for preliminary and then accepted modification of VPSA method, which was employed for designing the pilot plant.

In light of above given data and further considerations here looms the complexity of the problem of practicable and efficient way of separating methane from mine gases.

\section{Remarks on Preparation of Raw Mine Gas}

The main stage of applied investigations was carried out jointly by the AGH University of Science and Technology, Kraków, Poland and the Silesian Coal Concern J.S.W, Poland as a grant of application character. A complex of applied investigations was based on abovepresented results of numerical and computer calculations as well as on laboratory experiments [5]. Transition from the laboratory scale to pilot scale was possible after introducing certain concept changes and then also technological modifications. Some of them were made on the module for cleaning and drying of raw gas. Water drops and solid contaminations were separated on preliminary filters. Gas was cooled whereas water condensate with oil was separated in a separator. The water condensate remains were also removed in the next separator. Pre-treated gas was directed to gas tank before the entry to the further module where gas underwent cleaning and drying.

Gas was thoroughly dried in that module, and following the original concept, carbon dioxide partly separated. The latter issue in mind, the investor and designer of the large industrial installation should decide whether to completely or only partly remove carbon dioxide from the gas. The decision should depend on whether technological (purity of product) or economic (total cost) reasons prevail. Here the $\mathrm{CO}_{2}$ content in raw gas should be $1-4$ vol\% $\mathrm{CO}_{2}$. The lower limit corresponds to $\mathrm{CO}_{2}$ content given in Table 2, whereas the upper one to values sometimes encountered, i.e. in the Coal Mine "Pniówek".

Table 2. Gas composition from gas removal from one of the hard coal mines in the Silesian Coal Basin JSW, Poland

\begin{tabular}{|c|c|}
\hline Component & Content [vol\%] \\
\hline $\mathrm{CH}_{4}$ & 50.89 \\
\hline $\mathrm{C}_{2} \mathrm{H}_{6}$ & 0.0 \\
\hline $\mathrm{C}_{3} \mathrm{H}_{8}$ & 0.0 \\
\hline $\mathrm{N}_{2}$ & 40.39 \\
\hline $\mathrm{CO}$ & 0.0008 \\
\hline $\mathrm{CO}_{2}$ & 1.37 \\
\hline $\mathrm{O}_{2}$ & 7.35 \\
\hline $\mathrm{H}_{2}$ & 0.0 \\
\hline Parameter & Value \\
\hline Calorific value $\mathrm{MJ} \mathrm{m}^{-3}$ (STP)* & 18.1 \\
\hline $\begin{array}{l}\text { Density on normal conditions } \mathrm{kg} \mathrm{m}^{-3} \\
\text { (STP) } *\end{array}$ & 1.002 \\
\hline Molecular mass kg/kmol & 22.41 \\
\hline Wobbe number $\mathrm{MJ} \mathrm{m}^{-3}$ & 20.56 \\
\hline $\mathrm{H}_{2} \mathrm{~S}, \mathrm{NO}_{\mathrm{x}}$, org. sulphur content & 0.0 \\
\hline Solids content $\mathrm{mg} \mathrm{m}^{-3}(\mathrm{STP}) *$ & $1 \div 2$ \\
\hline
\end{tabular}

* (STP) - standard: temperature T=273 K and pressure $\mathrm{P}=101.3 \mathrm{kPa}$

Owing to the fact that $\mathrm{CO}_{2}$ was adsorbed even better that methane, it was assumed in the adapted VPSA method that only partial separation of carbon dioxide to about 3 vol\% should suffice.

\section{Pilot Installation for Enriching Coal Bed Methane}

The following major design assumptions were made: raw gas flow rate by $35(\mathrm{STP}) \mathrm{m}^{3} / \mathrm{h}$ at pressure of about 1.0 bar and typically averaged values of the main components: 53 vol\% $\mathrm{CH}_{4}, 37$ vol\% $\mathrm{N}_{2}, 7$ vol\% $\mathrm{O}_{2}, 3$ vol\% $\mathrm{CO}_{2}$; installation product: high-methane gas $96 \mathrm{vol} \%$ $\mathrm{CH}_{4}$, productivity: 18.3 vol\% (STP) $\mathrm{m}^{3} / \mathrm{h}$; working time of installation: average $5000 \mathrm{~h} /$ year, localization of installation: Coal Mine "Pniówek", Poland at Mine's Demethanization Research; wear index per 1000 (STP) $\mathrm{m}^{3}$ high-methane gas: electrical energy - $400 \mathrm{kWh}$, mine gas - 1910 (STP) $\mathrm{m}^{3}$, cooling water - $17 \mathrm{~m}^{3}$; working temperature: 283-293 K. 
Organization of gas stream flows in the installation plays an important role in the technology based on the VPSA method. The gas streams in that process were balanced in particular spots of the planned installation and were then verified on the pilot plant.

The diagram of gas streams in the first version VPSA process according to presented above process operations is presented in Figure 1. Two methane gas compressors, rotary wave vacuum pumps and Roots blower were used in the installation. An automatic control system with programmable controller was also applied.

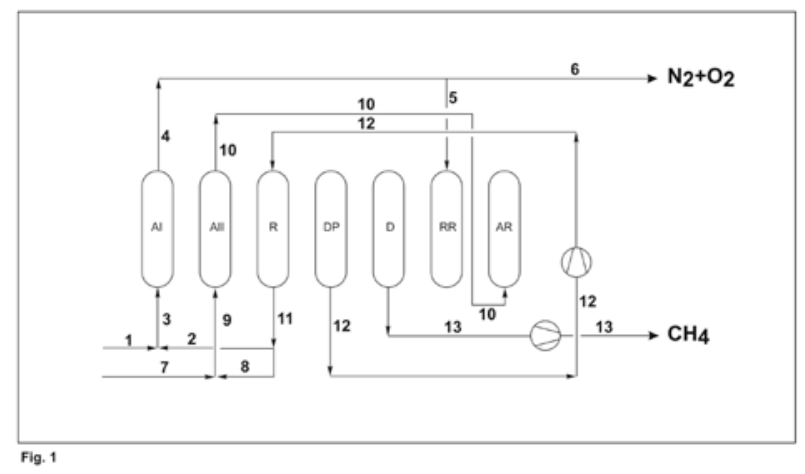

Figure 1. Scheme of gas stream in the first version of VPSA process

1 - cleaned gas for operation (AI), 2 - gas from operation (R) for operation (AI), 3 - total gas for operation (AI), 4 - low-methane gas from operation (AI), then separated into: 5 - gas for operation (RR), 6 waste gas, 7 - cleaned gas for operation (AII), 8 - gas from operation (R) for operation (AII), 9 - total gas for operation (AII), 10 - gas from operation (AII) for operation (AR), 11 - gas from operation (R), 12 - recirculated gas from operation (DP) for operation (R), 13 - gas from operation (D

\subsection{Accepted modification of the VPSA Method}

After construing the pilot plant, the installation was subjected to preliminary operation followed by first analyses. Those analyses revealed that a relatively high carbon dioxide content of ca. 4 vol\% $\mathrm{CO}_{2}$ was observed in a significantly variable composition of raw gas from the Coal Mine "Pniówek", Poland.

As already noted, such high $\mathrm{CO}_{2}$ contents would require carbon dioxide removal, especially in the case of industrial installations, with standard adsorption methods. However, using such methods for small gas quantities as in the pilot plant, would not be economically justified (additional cost). An acceptable compromise solution was selected. Changes were made in reference to the preliminary concept to improve the cleaning of the gas from the major part of oxygen and carbon dioxide through the pressure swing adsorption (PSA) method in the preliminary module. Besides, major changes were introduced in conducting the VPSA process itself. Thus, the PSA process of cleaning and drying was realized in the following technological operations:

- (RR) feedback filling: mine gas with adsorber VPSA which was in a minimum a few second break of its operation introduced to adsorber PSA, where the pressure simultaneously increases;

- (A) adsorption: compressed mine gas is delivered to adsorber PSA, and the feed gas runs to VPSA adsorber, where technological operation (A+AR) takes place;
- (PD) desorption by lowering the pressure: waste gas is discharged at the bottom of the adsorber;

- (P) washing: decompressed low-methane gas is supplied at the top of the adsorber from the tank, where gas from $(\mathrm{A}+\mathrm{AR})$ operation in module VPSA is stored;

Moreover, this module was better integrated with the main VPSA module in the installation. Besides, the filling and adsorption operations in module VPSA do not need to be separated. It was operation $(A+A R)$, which was assumed instead of two technological operations (AR) and (A/AR) present in the previous modification of the VPSA process. Attention was paid to the role of low-methane gas leaving the adsorber VPSA after that operation. The reduction of the number of technological operations resulted in lowering the number of adsorbers in the basic VPSA module to four, which also was a significant technological change. Besides, partial desorption operation was assumed to take place in two stages of pressure lowering: (DS) and (DR), depending on the required purity degree of product. The scheme of modified streams of gas in the installation and schedule for process were presented in Figure 2.
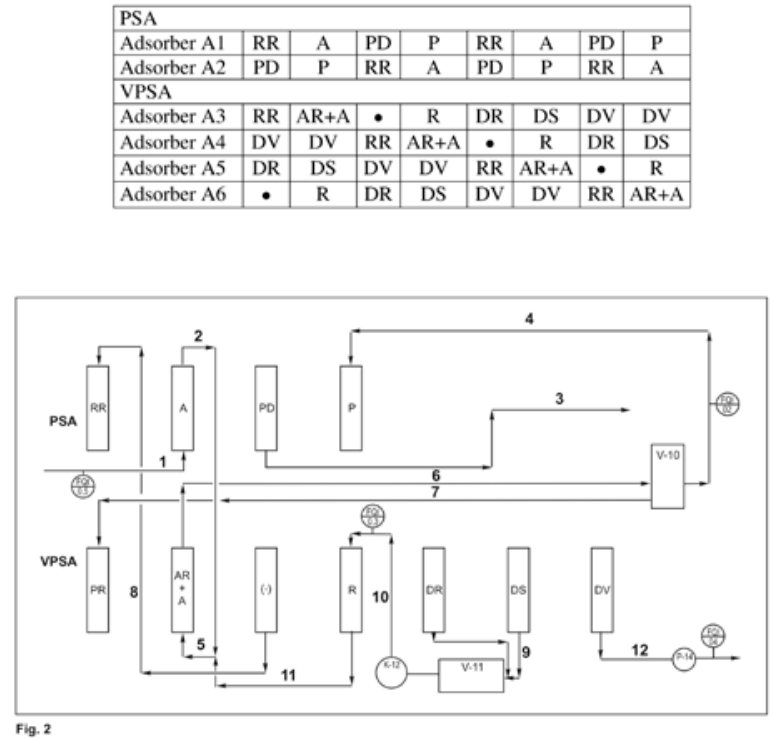

Figure 2. Scheme of modified gas stream flows and schedule for process in cycles PSA and VPSA

PSA: 1 - mine raw gas for operation (A), 2 - cleaned mine's gas from operation (A), 3 - waste gas from operation (PD), 4 - low-methane gas from tank V-10 for operation (P)

VPSA: 5 - mixture of gas from operation (A) in cycle PSA and from operation (R), 6 - low-methane gas from operation (A+AR) to tank V-10, 7 - low-methane gas from tank V-10 for operation(PR), 8 - gas from adsorber, which was in a short-term idle time (directed to operation (RR) of cycle PSA), 9 - gas from partial desorptions (DR) and (DS), 10 - gas re-circulated from tank V-11 after compression with a compressor K12, 11 - gas from operation (R), 12 - gas as a high-methane product from operation (DV), FQI - rotameter

Therefore the VPSA processes were realized in the following technological operations:

- (RR) feedback refilling of adsorber

- $(\mathrm{AR}+\mathrm{A})$ filling with feed gas and adsorption

- $(\bullet)$ a few second break in the process owing to the pressure state in the adsorbers

- $(\mathrm{R})$ rinsing of adsorbers 
- (DR) partial desorption: first stage of lowering pressure in adsorber

- (DS) partial desorption: second stage of lowering pressure in adsorber

- (DV) vacuum desorption

With those modifications, experimental tests were made on the pilot plant. The VPSA process was controlled with the following variable programmable parameters: time of each particular operation, time of cycle sequences. Among the regulated parameters were: adsorption final pressure, final pressure in desorption stages, filling time and the flow rate of low-methane gas. They were related with the following parameters:

- maximum and minimum pressure of rinsing operation (R),

- pressure of feedback refilling operation (RR),

- flow rate feed,

- re-circulated gas flow rate,

- high-methane gas flow rate.

It is worth noting that performing operations of feedback refilling (RR) was necessary. Moreover, by regulating the cycle parameters it was stated that the pressure $\mathrm{P}_{\mathrm{RR}}$ in this operation should be a little higher than the pressure $\mathrm{P}_{\mathrm{DR}}$ in the first operation of partial desorption. By fulfilling this condition the methane losses in the process are lower. An important meaning in the research had the pressure history profile. The changes of the pressure in time were registered and interpreted in each process operation.

\subsection{Criterial Parameters of VPSA Process}

Considerable variability of mine gas composition created certain problems to be solved during experiments. One of the solutions was, e.g. regulation of gas stream circulation in the installation. Certain amounts of desorbed gas had to be re-circulated to the rinsing operation process (R) and some quantity of lean-methane gas after adsorption was discharged from the installation, causing methane losses.

Among the criteria, which were used for optimization of work conditions of the installation were the following parameters:

- $\mathrm{Q}_{\mathrm{CH}_{4}+\mathrm{CO}_{2}}^{\mathrm{F}}$ sum of molar quantity of $\mathrm{CH}_{4}$ and $\mathrm{CO}_{2}$ introduced with feed gas in the preliminary module (PSA), i.e. sums expressed in $\mathrm{mol} / \mathrm{S}^{*}$;

$$
\mathrm{Q}_{\mathrm{CH}_{4}}^{\mathrm{F}}=\frac{1}{\mathrm{~N}} \frac{1000}{22.4}\left(\mathrm{Q}_{\mathrm{A}} \mathrm{y}_{\mathrm{CH}_{4}}^{\mathrm{A}}+\mathrm{Q}_{\mathrm{DV}} \mathrm{y}_{\mathrm{CH}_{4}}^{\mathrm{DV}}\right)
$$

and

$$
\begin{gathered}
\mathrm{Q}_{\mathrm{CO}_{2}}^{\mathrm{F}}=\frac{1}{\mathrm{~N}} \frac{1000}{22.4}\left(\mathrm{Q}_{\mathrm{A}} \mathrm{y}_{\mathrm{CO}_{2}}^{\mathrm{A}}+\mathrm{Q}_{\mathrm{DV}} \mathrm{y}_{\mathrm{CO}_{2}}^{\mathrm{DV}}\right) \\
\mathrm{Q}_{\mathrm{CH}_{4}+\mathrm{CO}_{2}}^{\mathrm{F}}=\mathrm{Q}_{\mathrm{CH}_{4}}^{\mathrm{F}}+\mathrm{Q}_{\mathrm{CO}_{2}}^{\mathrm{F}}
\end{gathered}
$$

where:

$\mathrm{Q}_{\mathrm{A}}$ - gas flow rate from adsorption, $\mathrm{m}^{3}$ (STP) $\mathrm{h}^{-1}$

$y_{\mathrm{CH}_{4}}^{A}$ - methane content in low-methane gas after adsorption, mol

$y_{\mathrm{CH}_{4}}^{\mathrm{DV}}$ - methane content in high-methane gas, mol
$y_{\mathrm{CO}_{2}}^{A}$ - carbon dioxide content in low-methane gas after adsorption, mol

$y_{\mathrm{CO}_{2}}^{\mathrm{DV}}$ - carbon dioxide content in high-methane gas, mol

- $\mathrm{Q}_{\mathrm{CH}_{4}+\mathrm{CO}_{2}}^{\mathrm{S}}$ sum of molar quantity of $\mathrm{CH}_{4}$ and $\mathrm{CO}_{2}$ at the end of rinsing operation $(\mathrm{R})$ with gas from desorption operations (DP) and (DV), i.e. sums expressed in mol/S*:

$$
\mathrm{Q}_{\mathrm{CH}_{4}}^{\mathrm{S}}=\frac{1}{\mathrm{~N}} \frac{1000}{22.4}\left(\mathrm{Q}_{\mathrm{CH}_{4}}^{\mathrm{DP}} \mathrm{y}_{\mathrm{CH}_{4}}^{\mathrm{DP}}+\mathrm{Q}_{\mathrm{DV}} \mathrm{y}_{\mathrm{CH}_{4}}^{\mathrm{DV}}\right)
$$

and

$$
\begin{gathered}
\mathrm{Q}_{\mathrm{CO}_{2}}^{\mathrm{S}}=\frac{1}{\mathrm{~N}} \frac{1000}{22.4}\left(\mathrm{Q}_{\mathrm{CO}_{2}}^{\mathrm{DP}} \mathrm{y}_{\mathrm{CO}_{2}}^{\mathrm{DP}}+\mathrm{Q}_{\mathrm{DV}} \mathrm{y}_{\mathrm{CO}_{2}}^{\mathrm{DV}}\right) \\
\mathrm{Q}_{\mathrm{CH}_{4}+\mathrm{CO}_{2}}^{\mathrm{S}}=\mathrm{Q}_{\mathrm{CH}_{4}}^{\mathrm{S}}+\mathrm{Q}_{\mathrm{CO}_{2}}^{\mathrm{S}}
\end{gathered}
$$

where:

$y_{\mathrm{CH}_{4}}^{\mathrm{DP}}$ - methane content in gas after partial desorption, mol

$y_{\mathrm{CO}_{2}}^{\mathrm{DP}}$ - carbon dioxide content in gas after partial desorption, mol

An important criterial parameter connected with economic aspect is the ratio of recycle gas flow rate to feed gas flow rate $\mathrm{Q}_{\mathrm{R}} / \mathrm{Q}_{\mathrm{F}}$. Re-circulation is expensive as it requires additional costs of gas compression. The ratio of quantitative sum of $\mathrm{CH}_{4}$ and $\mathrm{CO}_{2}$ re-circulated with gas in operation ( $\mathrm{R}$ ) to quantitative sum of those components in feed gas at VPSA entry is criterially important:

$$
\mathrm{q}=\frac{1}{\mathrm{Q}_{\mathrm{CH}_{4}+\mathrm{CO}_{2}}^{\mathrm{F}}}\left[\frac{1}{\mathrm{~N}} \frac{1000}{24} \mathrm{Q}_{\mathrm{R}}\left(\mathrm{y}_{\mathrm{CH}_{4}}^{\mathrm{DP}}+\mathrm{y}_{\mathrm{CO}_{2}}^{\mathrm{DP}}\right)\right]
$$

where:

$\mathrm{q}$ - recycle gas ratio

$\mathrm{N}$ - number of cycle sequences per hour, $\mathrm{S}^{*} \mathrm{~h}^{-1}$

$\mathrm{Q}_{\mathrm{R}}$ - recirculation gas flow rate, $\mathrm{m}^{3}(\mathrm{STP}) \mathrm{h}^{-1}$

That parameter represents the division of working capacity of sorbent into capacity used for operation $(\mathrm{A}+\mathrm{AR})$ related with feed gas, and working capacity of sorbent applied for rinse operation (R). This was a list of the most important parameters, the values of which can be regulated in the pilot plant.

Parameters of product, i.e. gas enriched in methane were: average $\mathrm{CH}_{4}$ content (vol\%), average sum of inerts $\mathrm{N}_{2}+\mathrm{O}_{2}$ (vol\%), average $\mathrm{CO}_{2}$ content (vol\%) or possibly average $\mathrm{CH}_{4}+\mathrm{C}_{4} \mathrm{H}_{6}$ content after deducting $\mathrm{CO}_{2}$ (vol\%). The inerts content was calculated from the dependence:

$$
\mathrm{y}_{\text {in }}=\left(1-\mathrm{y}_{\mathrm{CH}_{4}}^{\mathrm{DV}}-\mathrm{y}_{\mathrm{CO}_{2}}^{\mathrm{DV}}\right) 100 \mathrm{vol} \%
$$

$$
\mathrm{DV} \quad \mathrm{DV}
$$

The average $\mathrm{CH}_{4}$ and $\mathrm{CO}_{2}$ contents, i.e. $\bar{y}_{\mathrm{CH}_{4}}, \overline{\mathrm{y}}_{\mathrm{CO}_{2}}$ in enriched gas were calculated as arithmetic means of values from chemical analyses of gases from vacuum desorption (DV). Moreover, the sum of methane and ethane content, making up the product with possibly noticeable presence of $\mathrm{C}_{2} \mathrm{H}_{6}$, was calculated be deducting $\mathrm{CO}_{2}$ content: 


$$
\mathrm{y}_{\mathrm{CH}_{4}+\mathrm{C}_{2} \mathrm{H}_{6}}=\left(1-\mathrm{y}_{\text {in }}\right) 100 \mathrm{vol} \%
$$

The efficiency of methane separation was an important factor, defined as:

$$
\eta=\left[1-\frac{\mathrm{Q}_{\mathrm{A}} \mathrm{y}_{\mathrm{CH}_{4}}^{\mathrm{A}}}{\mathrm{Q}_{\mathrm{A}} \mathrm{y}_{\mathrm{CH}_{4}}^{\mathrm{A}}+\mathrm{Q}_{\mathrm{DV}} \mathrm{y}_{\mathrm{CH}_{4}}^{\mathrm{DV}}}\right] 100 \%
$$

It should be emphasized that apart from methane content in product, the efficiency of methane separation in process is another basic criterion of evaluation of modified VPSA technology. The experiments in the pilot plant were made in view of obtaining high efficiency and highest purity of product.

\section{Results of Experiments Performed in Pilot Plant}

Experimental tests were performed in a few measurement series, when the pressure and duration time of specific operations of the VPSA process were regulated. For instance, in one series the time of the cycle sequence S* was shortened to experimentally deteriorate operating conditions of vacuum desorption, and to create conditions for checking the influence of time of the cycle sequence on the course of the process. In other series, the adsorption pressure was also lowered, disadvantageously for the process of methane enrichment. Accordingly, in the next series the adsorption pressure was increased and possibly high methane recovery values were searched for. In another series, at the increased adsorption pressure the final pressure of partial desorption was lowered, time of cycle sequence slightly increased.

The results of the experiments were worked out according to systematics, accounting for the role of above multicriteria parameters. The plots of average content: methane $\overline{\mathrm{y}}_{\mathrm{CH}_{4}}^{\mathrm{D}}$, carbon dioxide $\overline{\mathrm{y}}_{\mathrm{CO}_{2}}^{\mathrm{D}}$ and inerts $\overline{\mathrm{y}}_{\text {in }}$ in product versus sum of those feed gases $\mathrm{Q}_{\mathrm{CH}_{4}+\mathrm{CO}_{2}}^{\mathrm{F}}$ are presented in Figures 3 to 5.

The assumed denotations refer to plots, where e.g. in $\mathrm{D}$

Figure 3 the symbol $\bar{y}_{\mathrm{CH}_{4}}$ at axe stands for average $\mathrm{CH}_{4}$ content in produced high-methane gas. Similarly, symbols $\overline{\mathrm{y}}_{\mathrm{CO}_{2}}^{\mathrm{D}}$ and $\overline{\mathrm{y}}_{\mathrm{in}}$ at axes of the following plots refer to $\mathrm{CO}_{2}$ and inerts content in the produces high-methane gas. Moreover, on the Figure 3 we can observe a high number of points referring to the relation of average content of $\mathrm{CH}_{4}$ in the produced high-methane gas versus sum of molar quantity of $\mathrm{CH}_{4}$ and $\mathrm{CO}_{2}$ in the feed gas, within two different scopes of $\mathrm{CH}_{4}$ volumetric percent content. On this plot of slight less importance are specific individual points, because this figure concerns the presentation of general growth trend in this relation. It was observed that high-methane gas over 95-96 vol\% $\mathrm{CH}_{4}$ was obtained when the $\mathrm{Q}_{\mathrm{CH}_{4}+\mathrm{CO}_{2}}^{\mathrm{F}}$ value was bigger than $39 \mathrm{~mol} / \mathrm{S}$ * which corresponded to methane content equal to 54-57 vol\%. At lower methane concentrations in the feed gas, also the methane content in product was lower. The carbon dioxide content of 3.7-4.2 vol\% $\mathrm{CO}_{2}$ in the feed gas lowered methane content in enriched gas. A significant parameter was inerts content in methane-rich gas, i.e. when $\mathrm{Q}_{\mathrm{CH}_{4}+\mathrm{CO}_{2}}^{\mathrm{F}}$ was higher than $39 \mathrm{~mol} / \mathrm{S}^{*}$, then the inerts content in product was lower than 1 vol\%. Even if methane content in the feed gas were lower, i.e. 48-52 vol\% $\mathrm{CH}_{4}$, and if then the inerts content in the highmethane gas were slightly higher about 1.5 vol\%, then, accounting for the potential possibility of complete separation of $\mathrm{CO}_{2}$ from gas, the methane level of 97-98 vol\% $\mathrm{CH}_{4}$ in products could be potentially reached.

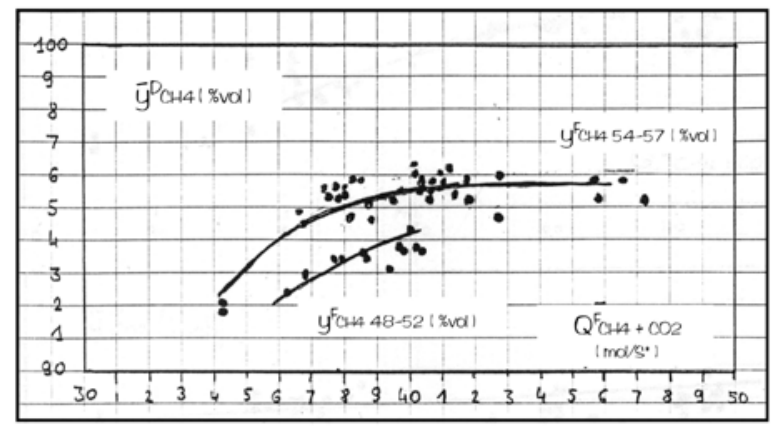

Fig. 3

Figure 3. Average methane content in enriched, high-methane gas vs. total quantity of methane and carbon dioxide introduced to module VPSA

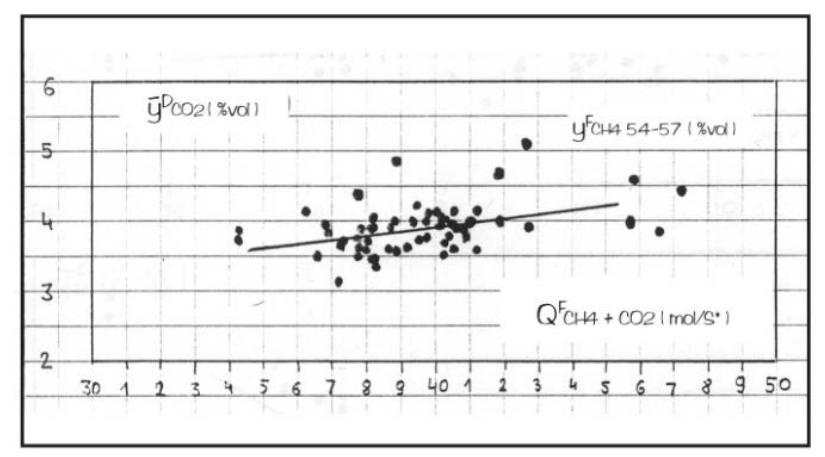

Fig. 4

Figure 4. Average carbon dioxide content in enriched, high-methane gas vs. total quantity of methane and carbon dioxide introduced to module VPSA

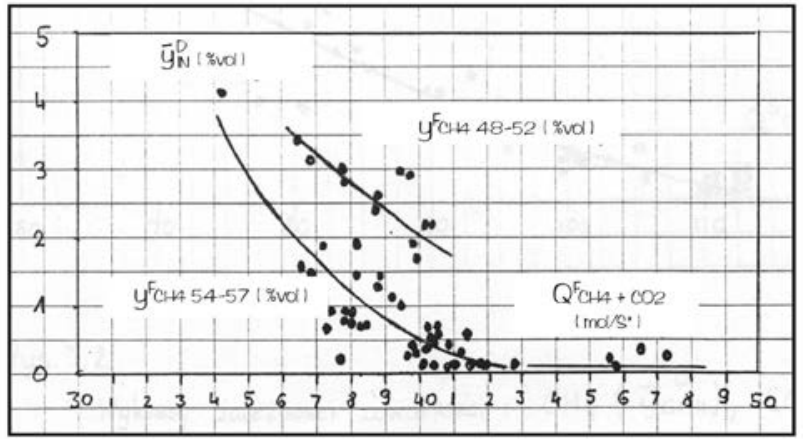

Fig. 5

Figure 5. Average content of inerts $\left(\mathrm{N}_{2}+\mathrm{O}_{2}\right)$ in enriched, high-methane gas vs. total quantity of methane and carbon dioxide introduced to module VPSA 
The average contents of methane $\overline{\mathrm{y}}_{\mathrm{CH}_{4}}$, carbon dioxide $\stackrel{-}{-}{ }_{\mathrm{y}_{\mathrm{CO}_{2}}}^{\mathrm{D}}$ and inerts $\stackrel{-}{\mathrm{y}}_{\text {in }}$ in high-methane product versus sum of quantity of $\mathrm{CH}_{4}$ and $\mathrm{CO}_{2}$ separated in desorption operations are plotted in Figures. 6 to 8 . Methane enrichment by 95-96 vol\% could be obtained for $\mathrm{Q}_{\mathrm{CH}_{4}+\mathrm{CO}_{2}}^{\mathrm{S}}$ higher than $95 \mathrm{~mol} / \mathrm{S}^{*}$, and then the inerts content in product is lower than $1 \mathrm{vol} \%$, and $\mathrm{CO}_{2}$ content reaches 4 vol\%. Then the increase of $\mathrm{Q}_{\mathrm{CH}_{4}+\mathrm{CO}_{2}}^{\mathrm{S}}$ quantity advantageously influenced the $\mathrm{CH}_{4}$ content in product, though $\mathrm{CO}_{2}$ content increases there, too.

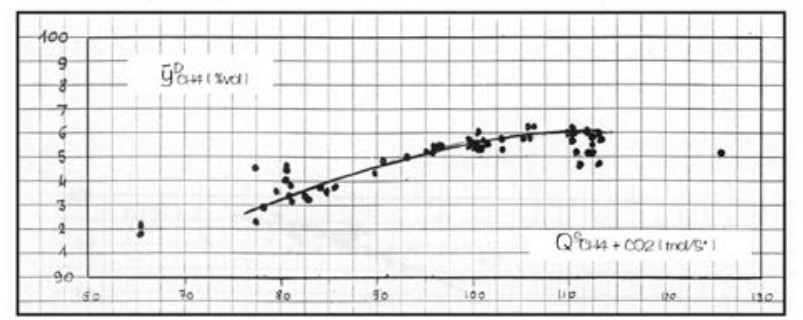

Fig. 6

Figure 6. Average content of methane in enriched, high-methane gas vs. total quantity of methane and carbon dioxide desorbed in process operations

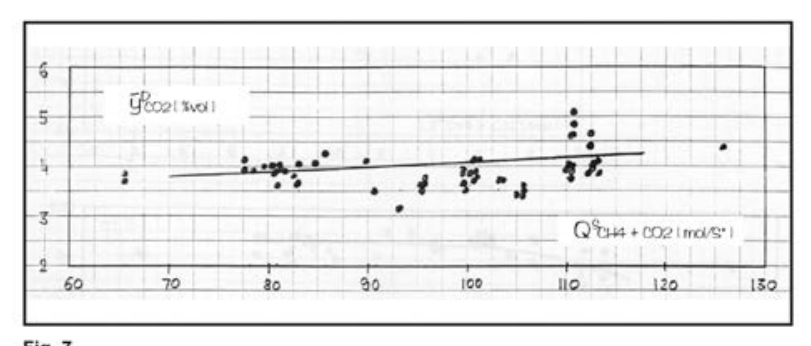

Fig. 7

Figure 7. Average content of carbon dioxide in enriched, high-methane gas vs. total quantity of methane and carbon dioxide desorbed in process operations

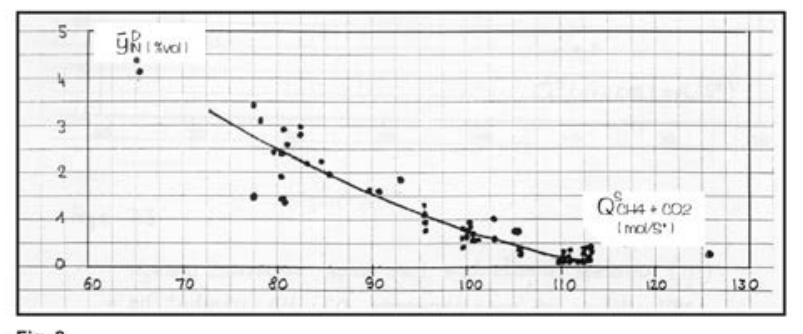

Figure 8. Average content of inters in enriched, high-methane gas vs. total quantity of methane and carbon dioxide desorbed in process operations

It can be concluded from the discussion of results presented in Figures. 6 to 8 that determined parameters $\mathrm{Q}_{\mathrm{CH}_{4}+\mathrm{CO}_{2}}^{\mathrm{F}}$ and $\mathrm{Q}_{\mathrm{CH}_{4}+\mathrm{CO}_{2}}^{\mathrm{S}}$ can be good and useful criteria for designing large-scale industrial installations. The plots of methane separation efficiency $\eta$ versus criterial parameters $\mathrm{Q}_{\mathrm{CH}_{4}+\mathrm{CO}_{2}}^{\mathrm{F}}$ and $\mathrm{Q}_{\mathrm{CH}_{4}+\mathrm{CO}_{2}}^{\mathrm{S}}$ are presented in Figures 9 to 10, respectively.

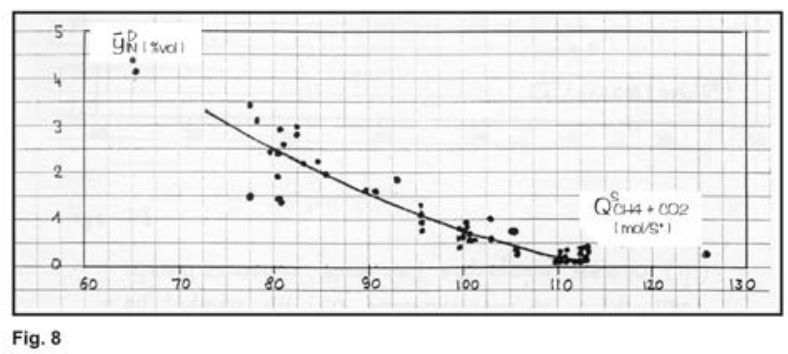

Figure 9. Efficiency of methane separation vs. total quantity of methane and carbon dioxide introduced to module VPSA

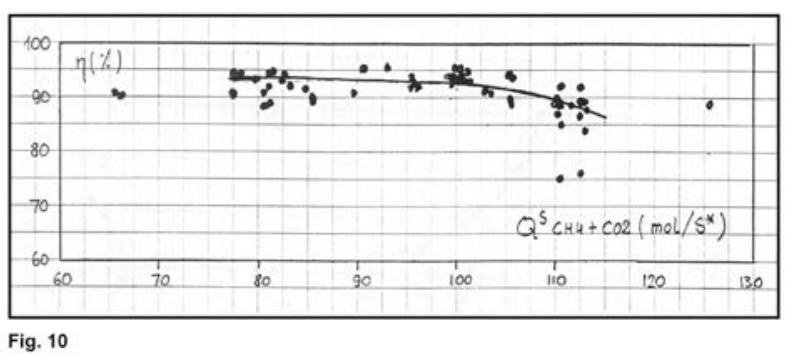

Figure 10. Efficiency of methane separation vs. total quantity of methane and carbon dioxide desorbed in process operations

The increase of $\mathrm{Q}_{\mathrm{CH}_{4}+\mathrm{CO}_{2}}^{\mathrm{F}}$ and $\mathrm{Q}_{\mathrm{CH}_{4}+\mathrm{CO}_{2}}^{\mathrm{S}}$ results in the drop of methane separation efficiency. The analysis of those plots reveals that to maintain the efficiency over $90 \%$, the $\mathrm{Q}_{\mathrm{CH}_{4}+\mathrm{CO}_{2}}^{\mathrm{F}}$ value should be lower than 40 $\mathrm{mol} / \mathrm{S}^{*}$, and $\mathrm{Q}_{\mathrm{CH}_{4}+\mathrm{CO}_{2}}^{\mathrm{S}}$ lower than $110 \mathrm{~mol} / \mathrm{S}^{*}$.

It was also an interesting idea to make a plot presented in Figure 11 on the basis of $\bar{y}_{\text {in }}$ versus $Q_{\mathrm{CH}_{4}+\mathrm{CO}_{2}}^{\mathrm{S}}$ plot in Figure 8, and $\eta$ versus $\mathrm{Q}_{\mathrm{CH}_{4}+\mathrm{CO}_{2}}^{\mathrm{S}}$ plot in Figure 10 .

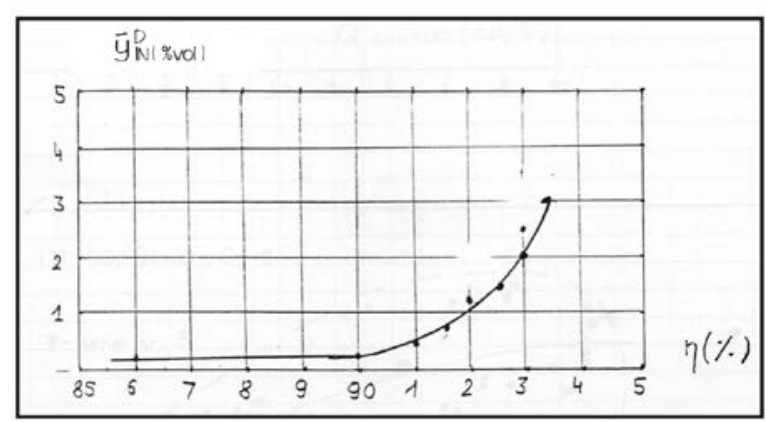

Fig. 11

Figure 11. Inerts $\left(\mathrm{N}_{2}+\mathrm{O}_{2}\right)$ content in high-methane gas vs. efficiency of methane separation

\section{$\mathrm{D}$}

The dependence of $\bar{y}_{\text {in }}$ versus $\eta$ is important here as it indicates that at the increasing methane separation efficiency grows the inerts content in the high-methane gas. Despite this, acceptable efficiency of $\eta=91 \%$ was 
achieved at low inerts content in high-methane gas D

$\overline{\mathrm{y}}_{\text {in }}=0.5 \mathrm{vol} \%$.

Another interesting result is the $\mathrm{q}$ ratio defining what quantity of $\mathrm{CH}_{4}$ and $\mathrm{CO}_{2}$ in gas partly enriched in methane from partial desorption operation is re-circulated to rinsing as compared to the quantities of those components introduced with feed gas to the VPSA module. Gas recirculation necessitates the use of additional compressor, beside the one for mine gas compression. The correlation of $\mathrm{q}$ with criterial parameter $\mathrm{Q}_{\mathrm{CH}_{4}+\mathrm{CO}_{2}}^{\mathrm{F}}$ and correlation of q with criterial parameter $\mathrm{Q}_{\mathrm{CH}_{4}+\mathrm{CO}_{2}}^{\mathrm{S}}$ were analyzed. It was revealed that for the recommended higher $\mathrm{Q}_{\mathrm{CH}_{4}+\mathrm{CO}_{2}}^{\mathrm{F}}=39-40 \mathrm{~mol} / \mathrm{S}^{*}$, the ratio $\mathrm{q}$ changes within 0.9-1.2, depending on $\mathrm{CH}_{4}$ content in the feed gas. This result is much better than the laboratory one. Similarly, for $\mathrm{Q}_{\mathrm{CH}_{4}+\mathrm{CO}_{2}}^{\mathrm{S}}=100-110 \mathrm{~mol} / \mathrm{S}^{*}$ the $\mathrm{q}$ ratio changes within 1.0-1.2. This result indicates that the compressor efficiency for gas re-circulation should be only about 20\% higher than the efficiency of raw gas compressor.

Moreover, the influence of above presented parameters on the course of enriching mine gases in methane in the pilot plant was investigated. It was observed, for instance, that the time of duration of cycle sequence $\mathrm{S}^{*}$ does not have substantial influence on the value of $\mathrm{Q}_{\mathrm{CH}_{4}+\mathrm{CO}_{2}}^{\mathrm{F}}$ at the same methane losses in the low-methane gas after adsorption. The increase of final adsorption pressure improves the efficiency of separation of gases, at the remaining parameters unchanged. At such a value of constant adsorption pressure, the increase of the pressure value which is the final pressure value at the partial desorption stage, unfavourably influences the gas separation conditions by, among others, increase of inerts content in product. It was also concluded that the final pressure of vacuum desorption should be as low as possible.

The investigation of the pilot plant was a source of interesting conclusions on the regulation of the lowmethane gas flow rate parameter. To avoid too big methane losses, attempts were made to maintain the $\mathrm{CH}_{4}$ content within 7-12 vol\% and keep the methane separation efficiency level at above 90\%. Moderate increase of the low-methane flow rate results in the increase of amount of desorbed gases, which lead to the increased amount of gases re-circulated in the process, and the consecutive drop of inerts content in high-methane gas. Above criteria were defined to optimize the work conditions of the installation both in the pilot plant and in scale industrial conditions. On this basis a patent was realized [6], containing innovative and original technological solutions.

\section{Conclusion}

Nitrogen with oxygen and carbon dioxide are the main gases which should be removed from the mixture of mine gases in order to recover methane. In the case of great quantities of those gases at industrial scale carbon dioxide should be eliminated with the use of standard absorption methods, just like in the case of natural gases.

In the presented investigations, economic reasons in view, carbon dioxide was only partly removed. The noxious presence of oxygen in the gaseous mixture was almost completely neutralized by employing the modified VPSA and PSA methods. That acceptable modification was a consequence of previous concept aimed at the improving the quality of high-methane product and increasing methane separation efficiency. According to the applied technological concept in the preliminary module PSA, the gases were thoroughly dried, part of $\mathrm{CO}_{2}$ was removed and excess of $\mathrm{O}_{2}$ liquidated to such an extent, that the gas entering the VPSA module was a mixture of only two components: methane and nitrogen with lower content of oxygen, which were separated. In the pilot plant in the Coal Mine "Pniówek" J.S.W. (Poland) a number of experiments were performed with the aim to establish criteria of optimum work conditions of the installation. Advantageous relations and dependences were defined between the quantity of gas re-circulated to process and feed gas. Attempts were made to minimize the methane losses in lean-methane gas leaving the installation after adsorption.

The criterial parameter values were calculated: $\mathrm{Q}_{\mathrm{CH}_{4}+\mathrm{CO}_{2}}^{\mathrm{F}}$ and $\mathrm{Q}_{\mathrm{CH}_{4}+\mathrm{CO}_{2}}^{\mathrm{S}}$ which may refer both to the pilot and industrial scale applications: $\mathrm{Q}_{\mathrm{CH}_{4}+\mathrm{CO}_{2}}^{\mathrm{F}}>35$ $\mathrm{mol} / \mathrm{S}^{*}, \mathrm{Q}_{\mathrm{CH}_{4}+\mathrm{CO}_{2}}^{\mathrm{S}}>95 \mathrm{~mol} / \mathrm{S}^{*}$.

Table 3. Results of measurements and calculations for a chosen experimental serie

\begin{tabular}{|c|c|}
\hline \multicolumn{2}{|c|}{ Feed gas to VPSA module } \\
\hline Inerts content $\left(\mathrm{N}_{2}+\mathrm{O}_{2}\right)(\mathrm{vol} . \%)$ & 43.45 \\
\hline $\mathrm{CO}_{2}$ content (vol.\%) & 3.48 \\
\hline $\mathrm{CH}_{4}$ content (vol.\%) & 53.07 \\
\hline Molar rate of $\mathrm{CO}_{2}: \mathrm{Q}_{\mathrm{CO}_{2}}^{\mathrm{F}}\left(\mathrm{mol} / \mathrm{S}^{*}\right)$ & 1.6 \\
\hline Molar rate of $\mathrm{CH}_{4}: \mathrm{Q}_{\mathrm{CH}_{4}}^{\mathrm{F}}\left(\mathrm{mol} / \mathrm{S}^{*}\right)$ & 38.7 \\
\hline $\begin{array}{l}\text { Sum of molar rates } \mathrm{CH}_{4}+\mathrm{CO}_{2} \text { : } \\
\qquad \mathrm{Q}_{\mathrm{CH}_{4}+\mathrm{CO}_{2}}^{\mathrm{F}}\left(\mathrm{mol} / \mathrm{S}^{*}\right)\end{array}$ & 40.3 \\
\hline \multicolumn{2}{|c|}{ Some parameters in sorbent bed } \\
\hline $\begin{array}{l}\text { Sum of molar rates } \mathrm{CH}_{4}+\mathrm{CO}_{2} \text { : } \\
\qquad \mathrm{Q}_{\mathrm{CH}_{4}+\mathrm{CO}_{2}}^{\mathrm{S}}\left(\mathrm{mol} / \mathrm{S}^{*}\right)\end{array}$ & 103.0 \\
\hline Recycle gas ratio $\mathrm{q}$ & 1.08 \\
\hline \multicolumn{2}{|c|}{ High-methane gas } \\
\hline Inerts content $\mathrm{N}_{2}+\mathrm{O}_{2}$ (vol.\%) & 0.58 \\
\hline Average $\mathrm{CO}_{2}$ content (vol.\%) & 3.70 \\
\hline Average $\mathrm{CH}_{4}$ content (vol.\%) & 95.72 \\
\hline Methane separation efficiency $\eta, \%$ & 90.9 \\
\hline
\end{tabular}

It was observed for so determined values of parameters that the value of an important criterial parameter, i.e. ratio $\mathrm{q}$ (methane rate of gas re-circulated to rinse operation vs. methane rate in feed gas to module VPSA) stayed within $\mathrm{q}=1.0-1.2$. In such conditions the high-methane gas, being the product of that installation, contained only 0.5 vol\% inerts $\left(\mathrm{N}_{2}+\mathrm{O}_{2}\right)$. The amount of carbon dioxide conditionally admitted to separation process equalled to 33.5 vol\% $\mathrm{CO}_{2}$, i.e. which lowered potential possibility of achieving very high purity of produced gas by the almost the same value. The methane content in product obtained 
in conditions assumed as optimum, was $96 \mathrm{vol} \% \mathrm{CH}_{4}$. The methane separation efficiency corresponding to those conditions changed within $90-92 \%$. In Table 3 are listed final results of measurements and calculations for one of series of experiments.

Such high-quality gas may be sent to the high-methane gas network. A preliminary project was elaborated for the future technical project of industrial scale installation

\section{Acknowledgement}

The author is grateful to the Ministry of Sciences and Higher Education in Warsaw, Poland for financial support of this work - Project No. 3T09 98C/4003

\section{References}

[1] Baksh, M.S.; Kapoor, A.; Yang, R.T. A new composite sorbent for methane-nitrogen separation. Sep. Sci. Technol., 25 (7-8): 845,1990

[2] Ruthven, D.M.; Farooq, S.; Knaebel, K.S., Pressure Swing Adsorption, (VCH); Canada, 1993

[3] Reinhold, H.E.; Knaebel, K.S. Separation of gases by pressure swing adsorption,. U.S. Patent 5,792,239,1998

[4] Reinhold, H.E. Pressure Swing Adsorption method and system for separating gas component, U.S. Patent 0190290 A I, 2008

[5] Olajossy, A.; Gawdzik, A.; Budner, Z.; Dula, J., Methane separation from coal mine methane gas by vacuum pressure swing adsorption. Trans. IChemE, 81 (Part A); 474, 2003

[6] Olajossy, A.; Budner, Z.; Budner, H. Sposób wydzielania metanu z gazów kopalnianych pochodzących $\mathrm{z}$ pokładów węgla kamiennego. Polish Patent PL 200383,2008 